\title{
Tamizaje fitoquímico de las hojas de Passiflora edulis Passifloraceae
}

\author{
Wendy Piura ${ }^{1}$ \\ Jennifer Maradiaga, Nelly Palacios, Rosa Ponce ${ }^{2}$ \\ Ligia Medina $^{3}$
}

\section{RESUMEN}

A través de un sondeo etnobotánico realizado en la comunidad de Jalaca, municipio de Talanga, se conoció que la especie Passiflora edulis de la familia Passifloraceae, conocida comúnmente como maracuyá, es utilizada por la comunidad como antitetánico y sedante. La forma de preparación es por medio de una infusión de las hojas que se administra por vía oral.

Se realizó un protocolo de análisis para identificar las familias de metabolitos presentes en hojas, con el propósito de aportar datos químicos que avalen el uso tradicional que le da la comunidad a esta planta. A través de este estudio se demostró la presencia de flavonoides y heterósidos cianogenéticos, de los cuales ya se tenían reportes anteriores; pero no se observó la presencia de antraquinonas y alcaloides, compuestos también reportados para esta especie en estudios posteriores. Consideramos importante este tipo de estudios que avalen el uso tradicional de las plantas medicinales.

Palabras claves: maracuyá, Passiflora edulis, metabolitos secundarios, análisis fitoquímico.

\section{ABSTRACT}

Through an ethnobotanical survey in the community of Jalaca, Talanga we learned that the specie of Passiflora edulis of the family Passifloraceae commonly known as "Passion fruit" is used by the community as antitetanus and sedative. The manner of preparation is by an infusion of the leaves that are administered orally. A protocol of analysis were performed to identify the families of metabolites in leaves in order to provide chemical data to support the traditional use that gives this plant in

\footnotetext{
${ }^{1}$ Instructora de laboratorio, Departamento de Control Químico, Facultad de Química y Farmacia, UNAH.

${ }^{2}$ Estudiantes de Farmacognosia I, Departamento de Control Químico, Facultad de Química y Farmacia, UNAH.

${ }^{3}$ Asesora, Departamento de Control Químico, Facultad de Química y Farmacia, UNAH. Contacto: liamel94@yahoo.com
} 
the community. Through this study, we showed the presence of flavonoids and cyanogenic glycosides which are demonstrated and previous reports, however we do not observed the presence of anthraquinones and alkaloids, compounds also reported for this species in previous studies. We consider that this type of study, that validates the traditional uses of medicinal plants to be important

Key words: Pasionfruit, Passiflora edulis, metabolitos secundarios, análisis fitoquímico.

\section{INTRODUCCIÓN}

La Passiflora edulis es una especie neotropical perteneciente a la familia Passifloraceae, es originaria de Brasil y fue introducida a otros países de América del Sur durante el siglo XIX. En este país se han reportado entre 150 y 200 especies. La Passiflora edulis conocida comúnmente como maracuyá, es una enredadera vigorosa, bastante rústica; presenta zarcillos redondos en forma de espiral; hojas simples, alternas, dentadas; flores hermafroditas de 3 sépalos, color blanco verdoso, 5 pétalos blancos y una corona; raíces totalmente ramificadas, sin raíz pivotante; el fruto es una baya oval o redonda, de entre 4 y $10 \mathrm{~cm}$ de diámetro, carnosa y jugosa, recubierta de una cáscara gruesa, cerosa, delicada e incomestible, el color presenta grandes diferencias entre variedades, la más frecuente en los países de origen es la amarilla, clasificada como $P$. edulis (Rozas, 1989).

La información etnofarmacológica revela que hojas y flores de P.edulis han sido utilizadas en la medicina tradicional como sedante, en el tratamiento de bronquitis y tos (Pamplona, 2008). Mediante una encuesta aplicada en la comunidad de Jalaca, Talanga, se observó que una de especies más utilizadas en medicina natural es la P.edulis, conocida por la comunidad como maracuyá, cuyas hojas se usan para el tratamiento del tétano, infusión de hojas y flores es indicada como sedante, en el tratamiento de la epilepsia, insomnio, hipertensión, diurético, dolores estomacales y fiebre (Pamplona, 2008). Un estudio fitoquímico previo de P.edulis demuestra la presencia de glucósidos, entre ellos: glucósidos flavonoides como la vitexina, glucósidos cianogénicos, derivados cumarínicos, fenoles, carotenoides y trazas de aceites volátiles (Rojas, 2011).

\section{METODOLOGÍA}

Estudio descriptivo y trasversal para determinar la presencia/ausencia de metabolitos secundarios presentes en las hojas de Passiflora edulis. El material vegetal se sometió a una digestión y posteriormente a maceración con etanol al 95 
$\%$. Se realizaron pruebas de identificación de alcaloides, flavonoides, antraquinonas, cianogenéticos, así como los test de control de calidad materia extraña y materia extraíble.

\section{Población}

La selección del taxón se realizó a través de un sondeo etnobotánico para identificar las especies y sus usos medicinales más comunes en la región. La metodología de recolección de la información se basó en entrevistas personales a miembros de diferentes edades y sexo de la comunidad, usando como guía un cuestionario estructurado con preguntas abiertas.

La información recolectada incluye nombre común, parte de la planta utilizada, método de preparación y usos de diferentes plantas medicinales. Posteriormente, se seleccionó el taxón Passiflora edulis como especie de estudio, tomando como criterio la ausencia de reportes fitoquímicos y la relevancia del uso etnobotánico reportado para dicha especie.

\section{Entorno}

El sondeo etnobotánico, la recolección del material vegetal y el montaje de la muestra de herbario se llevó a cabo en el mes de julio de 2011, en época lluviosa, en la comunidad de Jalaca, Talanga, departamento de Francisco Morazán.

\section{Intervenciones}

El análisis fitoquímico preliminar de la planta seleccionada, se realizó en el laboratorio de Farmacognosia I, Departamento de Control Químico, Facultad de Química y Farmacia, aplicando la metodología utilizada que se describe a continuación (Cáceres, 2003).

La identificación taxonómica del material vegetal fue realizada por el Dr. Paul House, en el herbario Cyril Hardy Nelson Sutherland TEFH. Se depositó un ejemplar de respaldo en el herbario de la Facultad de Ciencias Químicas y Farmacia de la UNAH.

\section{Procesamiento del material vegetal}

Las hojas se sometieron a un proceso de secado bajo sombra a temperatura ambiente; después se pulverizaron utilizando un molino manual y se envasó en un recipiente de vidrio herméticamente cerrados y debidamente rotulado. 


\section{Métodos de extracción e identificación}

$100 \mathrm{~g}$ de hojas secas y fragmentadas fueron colocadas en un recipiente color ámbar, sometidos a maceración dinámica por 3 horas y maceración estática por 7 días, utilizando como solvente de extracción etanol al $95 \%$, en cantidad suficiente para cubrir el material vegetal. Posteriormente se clarificó por filtración al vacío y se concentró. Al extracto se le realizaron las pruebas de identificación de alcaloides, flavonoides, antraquinonas, cianogenéticos, así como los test de control de calidad, entre ellos materia extraña y materia extraíble.

Se determinó la presencia/ausencia de los siguientes metabolitos secundarios:

1. Heterósidos cianogenéticos: se coloca la muestra en un beaker con agua destilada cubriéndolo con papel filtro. El papel se trata con el reactivo de Grignard (ácido pícrico $1 \%$ + carbonato de sodio 10\%). Se deja reposar de 30-40 minutos produciendo un color amarillo o naranja rojizo.

2. Flavonoides: reacción con álcali. En un tubo de ensayo se colocó extracto etanólico de la muestra y se agregó $1 \mathrm{ml}$ de $\mathrm{KOH} 2 \mathrm{~N}$; se obtiene una coloración amarillo intenso indicando presencia de flavonoides.

3. Flavonoides: reacción en gotas sobre papel filtro. Tomar una muestra de extracto etanólico con un capilar y colocar dos gotas sobre un papel filtro. La adición de los siguientes reactivos al papel indicará la presencia de flavonoides si se produce una reacción de color, con la adición de gotas de nitrato de plata se obtiene una coloración café y con el cloruro de aluminio se obtiene un color amarillo. La reacción con cloruro férrico es positiva cuando aparece una coloración verde y en contacto con los vapores de amoníaco se obtiene una coloración amarilla. La reacción de color indica presencia de los flavonoides.

4. Alcaloides: en unos tubos de ensayo se colocaron extractos etanólicos de la muestra y se agregaron $1 \mathrm{ml}$ del reactivo de Wagner, donde se debió haber formado un precipitado color café, indicando la presencia de alcaloides; con el reactivo de Dragendorff se esperó la formación de un precipitado color naranja; con los reactivos silicotúngstico y mayer la formación de un precipitado color crema; con el reactivo de Hager la formación de un precipitado color amarillo. En nuestra muestra, en ambos precipitados no se formaron, indicando la ausencia de alcaloides. 


\section{RESULTADOS}

Se encuestaron 30 personas de forma aleatoria, de esta información se encontró que el $80 \%$ de la población utiliza plantas medicinales como una alternativa para resolver problemas de salud y solo un $10 \%$ de la comunidad negó el uso de plantas medicinales. El $56 \%$ de la población utiliza las hojas P.edulis, en forma de infusión, para el tratamiento antitetánico y sedante. El $86 \%$ recolectan las hojas en el huerto de su casa y el $43 \%$ la usa en horas de la noche; el $63 \%$ también la utiliza como planta comestible.

Se realizó el control de calidad de materia extraña por medio de inspección directa ocular, obteniéndose $1.8 \%$ y un contendido de $870 \mathrm{mg}$ de materia extraíble/g de muestra. Los resultados de la determinación de grupos de metabolitos secundarios se muestran en el cuadro 1.

Cuadro 1. Análisis fitoquímico de la $P$. edulis

\begin{tabular}{|c|c|c|}
\hline Ensayo & Metabolito / evaluado & Presencia relativa \\
\hline Reacción de Borntraguer & Antraquinona & Negativo \\
\hline Wagner & Alcaloides & Negativo \\
\hline Dragendorff & Alcaloides & Negativo \\
\hline Silicotúngstico & Alcaloides & Negativo \\
\hline Hager & Alcaloides & Negativo \\
\hline Reactivo de Gringnard & Heterósidos cianogenéticos & Negativo \\
\hline Reacción de Shinoda & Flavonoides & Negativo \\
\hline Reacción con álcali & Flavonoides & Negativo \\
\hline $\begin{array}{l}\text { Reacción con ácido sulfúrico } \\
\text { concentrado }\end{array}$ & Flavonoides & Negativo \\
\hline $\begin{array}{l}\text { Reacción con ácido sulfúrico } \\
\text { concentrado y ácido bórico }\end{array}$ & Flavonoides & Negativo \\
\hline Nitrato de plata & Flavonoides & Negativo \\
\hline Cloruro de aluminio & Flavonoides & Negativo \\
\hline Cloruro férrico & Flavonoides & Positivo \\
\hline Vapores de amoníaco & Flavonoides & Positivo \\
\hline
\end{tabular}

Significado de las claves: - ausencia, + presencia. 


\section{DISCUSIÓN}

Utilizar etanol para realizar el macerado de hojas de P.edulis es una forma práctica y sencilla de extraer los metabolitos polares presentes en una planta. El análisis fitoquímico del extracto permitió comprobar la presencia de flavonoides y heterósidos cianogenéticos y no se detectó la presencia de alcaloides y antraquinonas, compuestos reportados en la monografía de esta droga. En la droga se reportan flavonoides como la vitexina a la cual se le ha estudiado por poseer actividad antitetánica, lo que justificaría este uso del maracuyá por la comunidad (Rojas, 2001).

\section{CONCLUSIONES}

De este estudio fitoquímico se puede concluir que la especie $P$. edulis produce flavonoides y heterósidos cianogenéticos compuestos reportados en la literatura revisada. Sin embargo, con los resultados de este estudio no se puede afirmar que la especie es responsable de la actividad sedante y antitetánica reportada por la comunidad de Jalaca. Para evaluar esta actividad se recomienda realizar ensayos in vivo en animales y humanos, además de continuar con el estudio fitoquímico para extraer, purificar y elucidar las especies químicas presentes en la planta.

\section{AGRADECIMIENTOS}

A las personas entrevistadas de la comunidad de Jalaca, quienes tuvieron la bondad de brindar su tiempo y aportar sus valiosos conocimientos. Asimismo, a Carolina Arévalo, Ligia Medina, Paul House y Marta Liliana Rodríguez, por la asesoría brindada.

\section{BIBLIOGRAFÍA}

Cáceres, A.; Gattuso, S.; Guerrero, N.; Solís, P. (2003). Manual de caracterización y análisis de drogas vegetales y productos fitoquímicos. OEA.

Desmarchelier, C. y Witting, F. (2000). Setenta plantas medicinales de la Amazonía peruana. Lima: Gráfica Bellido.

Jamir, T.; Sharma, H. y Dolui, A. (1999). Folklore medicinal plants of Nagaland. Fitoterapia, 999(70), 395-401. India.

Pamplona, J. (2008). Salud por las plantas medicinales. España: Safeliz.

Rojas, J.; Ronceros, S.; Palomino, R.; Tomás, G. y Chenguayen, J. (2006).

Efecto antihipertensivo y dosis letal 50 del jugo del fruto y de extracto etanólico de las hojas de P. edulis en ratas. An Fac Med, 67(3), 206-13. Lima. 